\title{
BIM-Based Construction Information Management Framework for Site Information Management
}

\author{
Dong-Gun Lee $(\mathbb{D}$, Ji-Young Park, and Sang-Hoon Song \\ Land \& Housing Institute, Korea Land and Housing Corporation, Bundang-gu, Republic of Korea \\ Correspondence should be addressed to Dong-Gun Lee; dk418@lh.or.kr
}

Received 9 August 2017; Revised 20 November 2017; Accepted 21 December 2017; Published 19 February 2018

Academic Editor: Sanjay Kumar Shukla

Copyright ( 2018 Dong-Gun Lee et al. This is an open access article distributed under the Creative Commons Attribution License, which permits unrestricted use, distribution, and reproduction in any medium, provided the original work is properly cited.

\begin{abstract}
Projects in the construction industry are becoming increasingly large and complex, with construction technologies, methods, and the like developing rapidly. Various different types of information are generated by construction projects. Especially, a construction phase requires the input of many resources and generates a diverse set of information. While a variety of IT techniques are being deployed for information management during the construction phase, measures to create databases of such information and to link these various different types of information together are still insufficient. As such, this study aims to suggest a construction information database system based on BIM technology to enable the comprehensive management of site information generated during the construction phase. This study analyzed the information generated from construction sites and proposed a categorization system for structuring the generated information, along with a database model for storing such structured information. Through such efforts, it was confirmed that such a database system can be used for accumulating and using construction information; it is believed that, in the future, the continual accumulation and management of construction information will allow for corporate-level accumulation of knowledge as opposed to the individual accumulation of know-how.
\end{abstract}

\section{Introduction}

Projects in the construction industry are becoming increasingly large and complex, with new construction technologies, methods, and the like developing rapidly. Furthermore, owners of construction projects are making increasingly diverse sets of demands while all related laws and regulations undergo rapid change. As a result of such advancements in construction technology and the growing complexity of the construction industry, efficient management of the diverse information generated from construction projects is becoming increasingly necessary. In particular, since the construction phase is the phase where the building begins to take shape based on the blueprints, a successful project requires comprehensive management of large quantities of information to allow the construction phase to succeed [1].

Due to the importance of information management, the construction industry utilizes a diverse array of IT techniques, and various studies and methods such as CIC (Computer
Integrated Construction), CALS (Continuous Acquisition and Life-cycle Support), and PMIS (Project Management Information System) exist in order to comprehensively manage the information that is generated during the course of construction. However, as a result of examining these studies, it is difficult to utilize the information due to the fact that the information generated in the construction industry is collected as one information such as e-documents. They merely focus on the visualization of data and are therefore insufficient in terms of establishing connections within the data [2-4].

BIM (building information modeling) exists to resolve the problems associated with construction information management techniques. While it can be said that BIM is a technique that uses a three-dimensional parametric modeling technique to consolidate the information generated during the construction phase into a database so as to facilitate connections between data points, it is currently used mainly for making various assessments and analyses that use 3D models such as interference assessment, sunshine analysis, viewing area analysis, and energy analysis. That is, while BIM 
is being effectively used for analyses that use $3 \mathrm{D}$ models, it is not being used for construction information management through the consolidation of construction information and database building. This may be attributed to the insufficiency of database systems for BIM information management and the lack of means to effectively link figure information and nonfigure information [5].

As such, this study proposes a means of effectively linking figure information, which is planning information, and nonfigure information, which is construction information, as well as a BIM-based database system for construction information, in order to facilitate effective accumulation of construction information and enhanced information management. In order to achieve the purposes of this study, analysis of the information generated during the construction phase is used to propose an information categorization system that orders uncategorized information along with a database system that gathers these structured data.

\section{Preliminary Considerations}

2.1. Problems of Documented Information from Construction Sites. Construction sites manage information generated during the construction phase by documenting such information [6]. However, these documents are numerous and diverse and often contain much overlapping information [7]. Some representative examples of documents generated by construction sites are daily labor reports and safety reports. Labor reports contain general information concerning the project such as the name of the construction project, date, weather, and temperature, in addition to constructionrelated information such as construction progress details, contractor output details, current state of equipment, and current state of material inputs and special information such as cautionary notes concerning the work. Safety reports contain general information such as the name of the construction project, date, and weather; work information such as the details of work to be done on that date; safety information such as safety inspection records, safety training details, and site manager safety inspection details; and special information such as cautionary notes concerning safety and any special notes.

Daily labor reports and safety reports contain overlapping general information: the name of the construction project, date, weather, and details of the work to be done on the date, and so on. As such, while the information generated from construction sites is managed in the form of various different documents, the information contained therein is connected to each other and often overlaps.

However, since the documents generated from construction sites are handled only as individual documents, it is difficult to use the information contained in these documents in a consolidated manner. Furthermore, since the documented information generated by a construction site is archived onsite at a document archive as physical documents or as computer files in a format chosen by the person responsible for preparing each document, the reality is that it is difficult to search through and use the information contained in each document.
A review of previous studies on the management of construction documents shows that, from the 1980s to 1990s, the main focus was on foundational research on EDI to digitize the construction industry so as to enhance the efficiency of construction work and the construction industry overall, in addition to foundational research on EDMS to comprehensively manage such information [8]. Furthermore, from the late 1990s to early 2000s, research efforts were focused on sharing documents and data, as well as webbased information sharing using XML and EDI [9-14], while research from the late 2000s onwards focused on searching through accumulated information and the effective use of data [15-17].

Analysis of previous studies has confirmed that, while current methods of construction information management propose measures to enhance the effectiveness of work analysis and/or document management in order to improve the efficiency of certain tasks or document exchanges, there is a lack of research on the management and use of the overlapping information contained in documents generated onsite. Furthermore, it was also confirmed that only those in charge of preparing the documents accurately comprehend the information contained within and that insufficient management of documented information limits the search, use, and consistency of information. As such, it is necessary to devise a systematic methodology for gathering the documented information that contains most of the information concerning construction sites so as to facilitate effective accumulation of construction information and to improve its usefulness and consistency, and in order to increase the usefulness of this accumulated documented information, it can be said that it is necessary to visualize both structural information and linked information such as BIM, as it is useful for direct searches on, and the use of, documented information.

\subsection{BIM for Construction Information Management. BIM is} based on Eastman's Building Description System from the 1970s and is developing into a technique that incorporates the concept of a virtual building that enables the consolidation and analysis of information through $3 \mathrm{D}$ modeling, from the planning stages all the way to maintenance and repairs.

Some of the advantages of BIM include its ability to allow for the accumulation of construction information through model data, which in turn allows for easy standardization and management of knowledge assets, as well as its ability to allow for data accumulation and management through a $3 \mathrm{D}$ model, contributing to communication between the parties involved in the construction, along with sharing and procuring materials between them, thus improving cooperation and contributing to effective information management. Furthermore, it establishes an automated environment for information management, reducing the resources needed for the preparation of drawings, quantity calculations, and various other aspects of construction management.

Among the studies on BIM, a system with the aforementioned advantages, a review of those involving onsite 


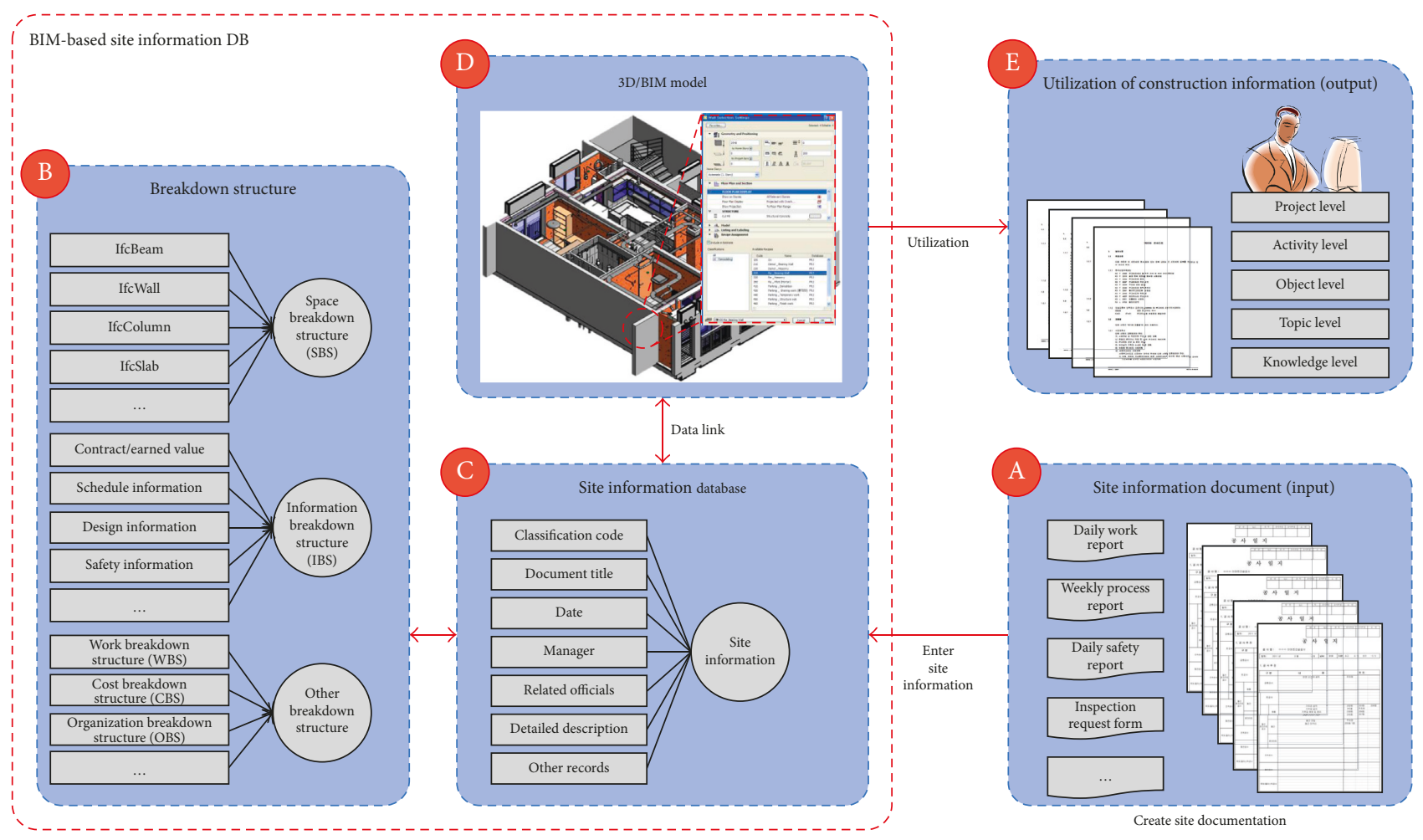

Figure 1: BIM-based construction database system.

information management through BIM shows the following: the study by Dawood et al. [18] suggested a resource-databased user interface and database system to combine AutoCAD and MS Project for the development of a consolidated database to allow for $4 \mathrm{D} / \mathrm{VR}$ process simulation, while Caldas et al. [19] suggested a data link system for connecting documented information and model data that is based on automatically categorizing documents using the IFC file system and a systematic analysis of MasterFormat to link them to BIM, thereby suggesting a linked framework between 2D models and documented information. Eastman et al. [20] suggested an information conversion system for structural information compatibility between the IFC file system and the standard American BIM system to facilitate smooth information sharing through the BIM model. Liu and Issa [21] considered a measure for smooth data compatibility between BIM model data and maintenance system data in order to apply planning-stage BIM model data to the maintenance system in order to enhance the usefulness of BIM during the maintenance and management phase. In order to apply BIM information to China's bidding system, Ma et al. [22] developed a process map and algorithm for linking BIM model data and the information needed for bidding based on an algorithmic analysis of the bidding system and verified the usefulness of said process map and algorithm, while Lin [23] suggested a BIM-based system for the management of construction knowledge during the construction phase that would enable the storage of information relevant to the construction phase using the BIM model.
Previous studies on BIM-based information management mainly focused on information compatibility between each phase of a construction project. For example, the studies focused on how information must be exchanged in order to utilize design phase BIM data for the structural BIM or the facilities and equipment BIM. Also, while previous studies were focused on the life cycle of buildings and thereby suggested frameworks for data compatibility and exchange throughout all of the phases of construction, they were rather insufficient in terms of realizing an actual, detailed system while also lacking research on database establishment and information consolidation for data accumulation and management during the construction phase, which is the phase that generates the most information among all of the phases of construction.

\section{Measure for the Establishment of a BIM- Based Construction Database}

It can be said that effective accumulation and management of documented information at a construction site exert a significant influence on efficiently progressing construction and accumulating construction know-how. As such, this study suggests a database system for construction information to manage such construction information. A BIM-based construction database will rearrange and accumulate documented information generated at construction sites through a categorization system and will link these data with the BIM model to enable the utilization of construction information. The overall 


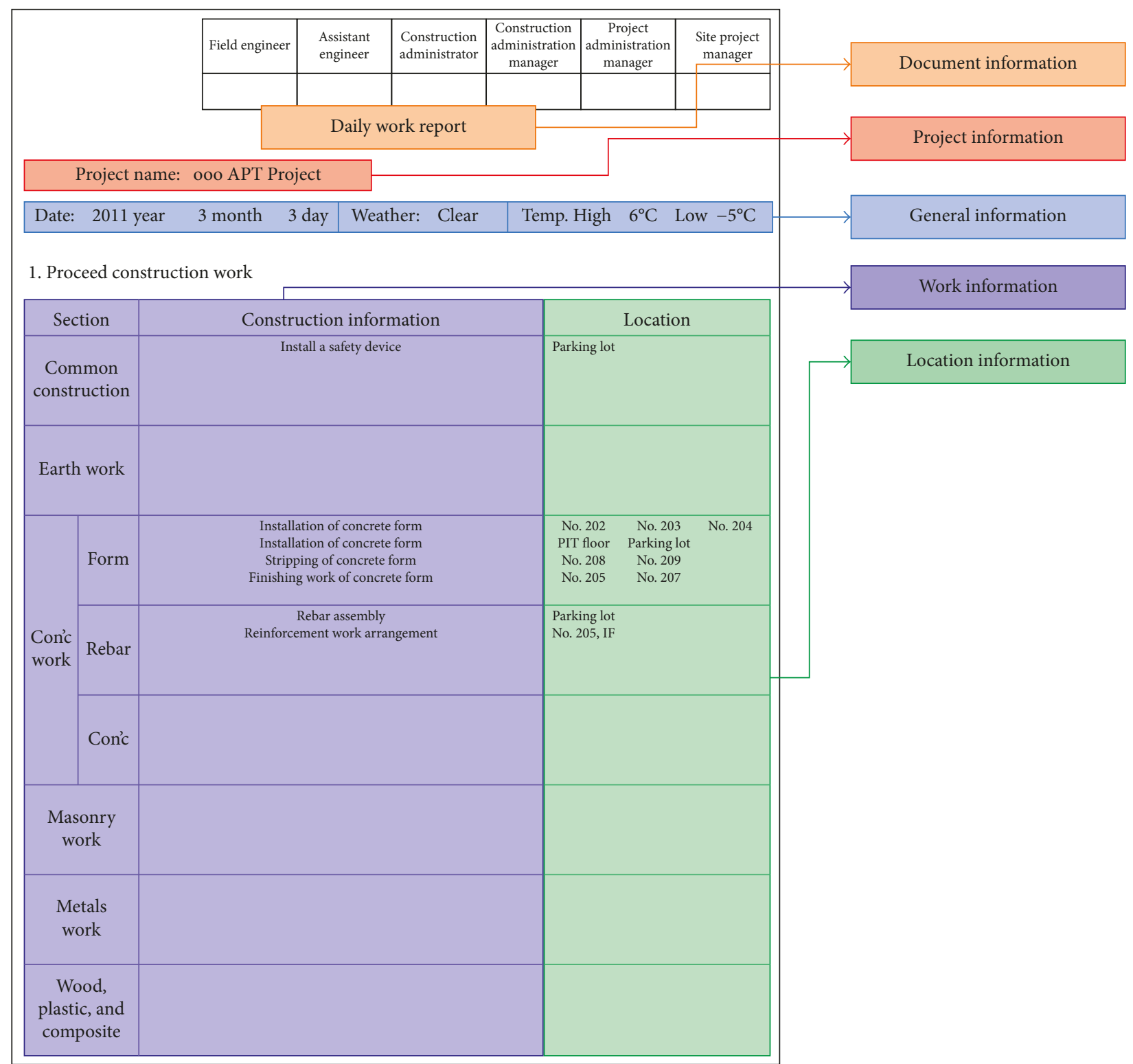

FIGURE 2: Information within site-generated documents (example: daily work report).

structure of such a BIM-based construction database is depicted in Figure 1.

The BIM-based construction database system as depicted in Figure 1 shows that the documents generated at construction sites as shown in Part A are each prepared by the document preparer, and such documents can be rearranged through a categorization system designed to categorize such information as shown in Part B, and then the rearranged documented site information is stored in the form of a database as shown in Part C. Such stored information is managed by linking it with the BIM model as shown in Part $\mathrm{D}$, and the construction data that are linked to the BIM model and stored can then be used by construction managers, and so on, as shown in Part E.

To explain this construction database system in more detail, if, for example, among the various site documents shown in Part A of Figure 1, the documents in question are daily work reports, then data such as the information structure (type of information), general information on the project, general information on the construction, information related to construction work, and space information are included. Figure 2 depicts the data contained in the documents generated at construction sites.

Such site-generated documents each contain diverse arrays of information, and since such information often overlaps with those contained in other documents, it is necessary to comprehensively manage such construction information in order to enhance consistency.

The information contained within site-generated documents needs to be categorized and gathered in accordance with the categorization system shown in Part B of Figure 1 in order to properly structure the information. For this purpose, this study has categorized documented information using the space breakdown structure (SBS) and the information 


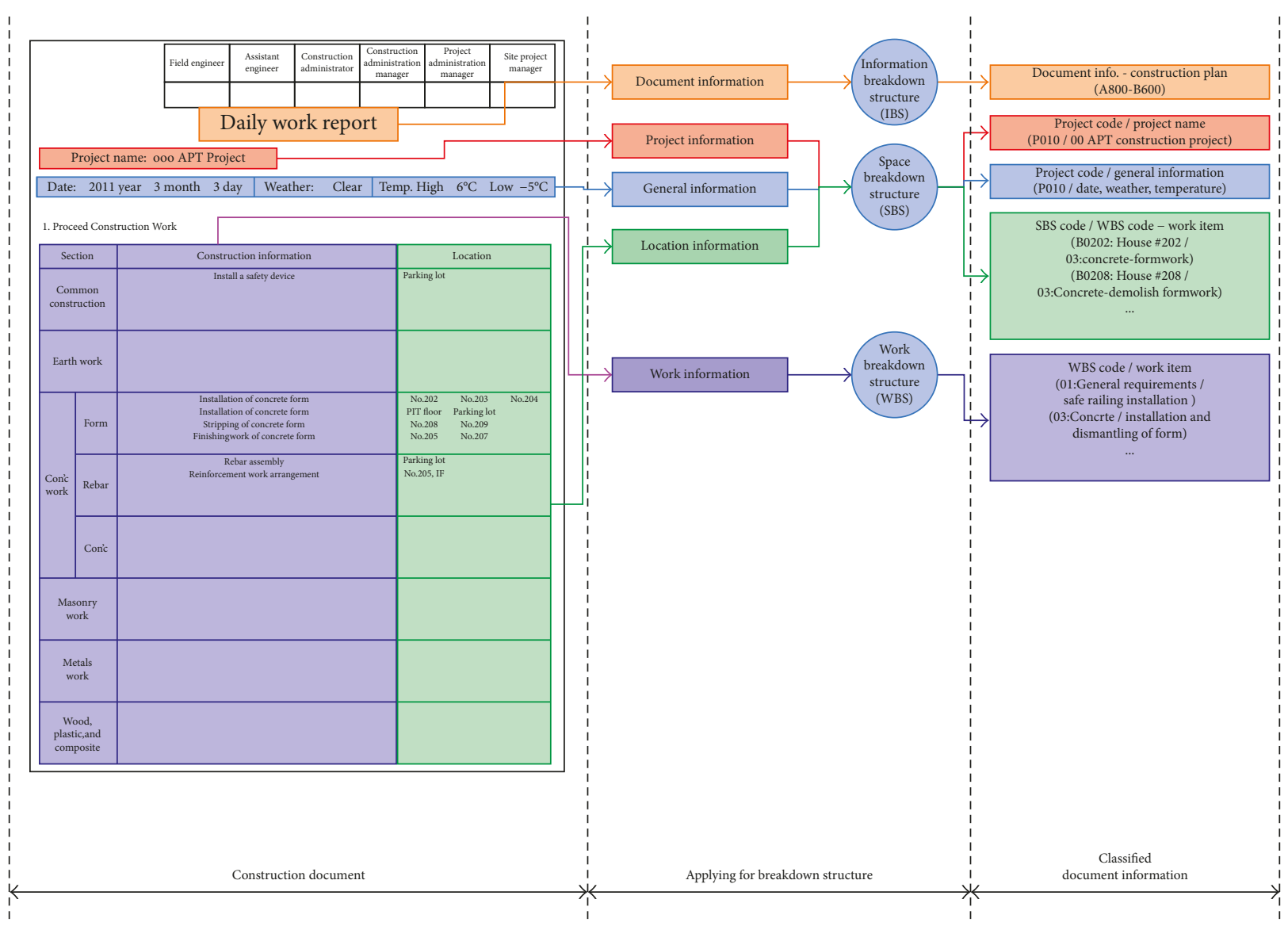

Figure 3: Application of categorization systems (example: daily work report).

breakdown structure (IBS), which were established through prior research. Figure 3 depicts the concept of categorizing the information contained in daily construction journals through said categorization systems.

The categorization of the information contained in daily work report facilitates the categorization of construction journals themselves through the IBS into the categories of "Documented Information-Building Plan"; more specifically, project information, general construction information, and space information can be categorized and included as project elements by the SBS, while general construction information can be linked to the project elements of the SBS and thereby categorized into "Project-General Construction Information (date, weather, temperature, etc.)." Furthermore, space information can be categorized and stored using the Space-Based System.

Documented information that is categorized in this manner is stored in the database shown in Part C of Figure 1, and the stored information can be stored in either the categorized documented information format or in an electronic document format for use. Figure 4 is an abstract depiction of the process in which construction data categorized through the categorization system are stored in the database.

Categorized data can be reordered into new data combinations from the database, increasing the usefulness of the information. Furthermore, electronic document information, which is stored in an electronic document format, is saved as is, allowing for the accumulation of nonstandard documented information in the database as well, offering a solution to the problems arising from document storage and management at construction sites (such as destruction or loss of documented information).

Documented information saved in the database is managed by connecting it to the BIM model, as shown in Part D of Figure 1. The construction information database is linked based on the Space-Based System and is matched 1:1 with the individual Objects of the BIM model, allowing for the storage of construction information through the BIM model.

There are various methods for linking the BIM model and the Space-Based System for construction information, including a method where links are established through the individual IDs within the IFC files of the BIM model, a method using the Object IDs provided by the BIM software that is used, a method where the Layer ID of the Object is used, and so on. Figure 5 depicts the concept of linking the BIM model with the construction information.

Once the BIM model and the construction information database are connected, construction information can be accumulated through each object of the BIM model as shown in Part E of Figure 1, and construction 


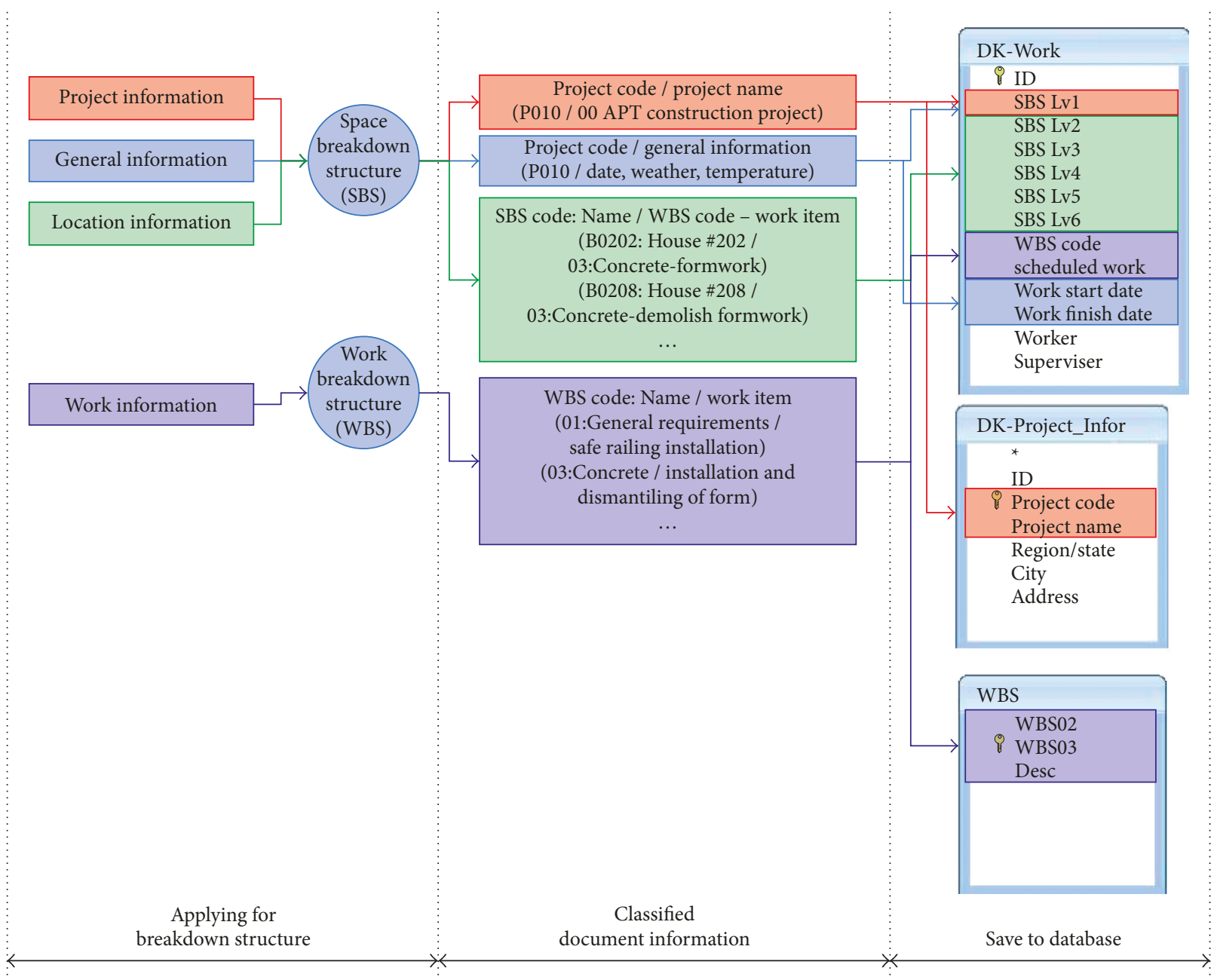

FIgURE 4: Example of storing categorized construction data in a database.

information can be verified through the BIM model. For example, when fractures form on a wall, the construction information, general construction information, and so on of the relevant framework can be checked through the SpacedBased System and the Information-Based System of the relevant construction project. Figure 6 depicts an example of using the BIM-based construction information database.

By gathering information on the building process, such a construction information database can be used to manage the construction information history for the building; in addition, storing the documents generated during the building process using this model allows for easy verification of construction information during the building process, and in particular, should claims or other issues arise, it can assist with the accumulation and management of claim-related documents through the BIM model.

\section{Establishment of a BIM-Based Construction Information Database System}

4.1. Construction Information Database System. In order to gather documented information on construction by connecting structural and nonstructural information, the BIM-based construction information database can be categorized into a space category, site information, work information, and a database for onsite documents, and such a database gathers information by interlinking the spacecategorized database with the site information database and the work information database through space category codes, with the space-categorized database at the core. Figure 7 is a conceptual depiction of the interlinking relationship of a BIM-based construction information database system.

In the case of documented information generated onsite that is difficult to structure into database form, the document itself can be transformed into an electronic document for management. That is, as shown in Part D of Figure 7, onsite documents are stored in the form of electronic documents, and by incorporating space information into such electronic documents through the space-based categorization system, the documents themselves can be linked with structural information and managed.

By using this concept to gather both standardized and nonstandardized data from the documents generated at the 


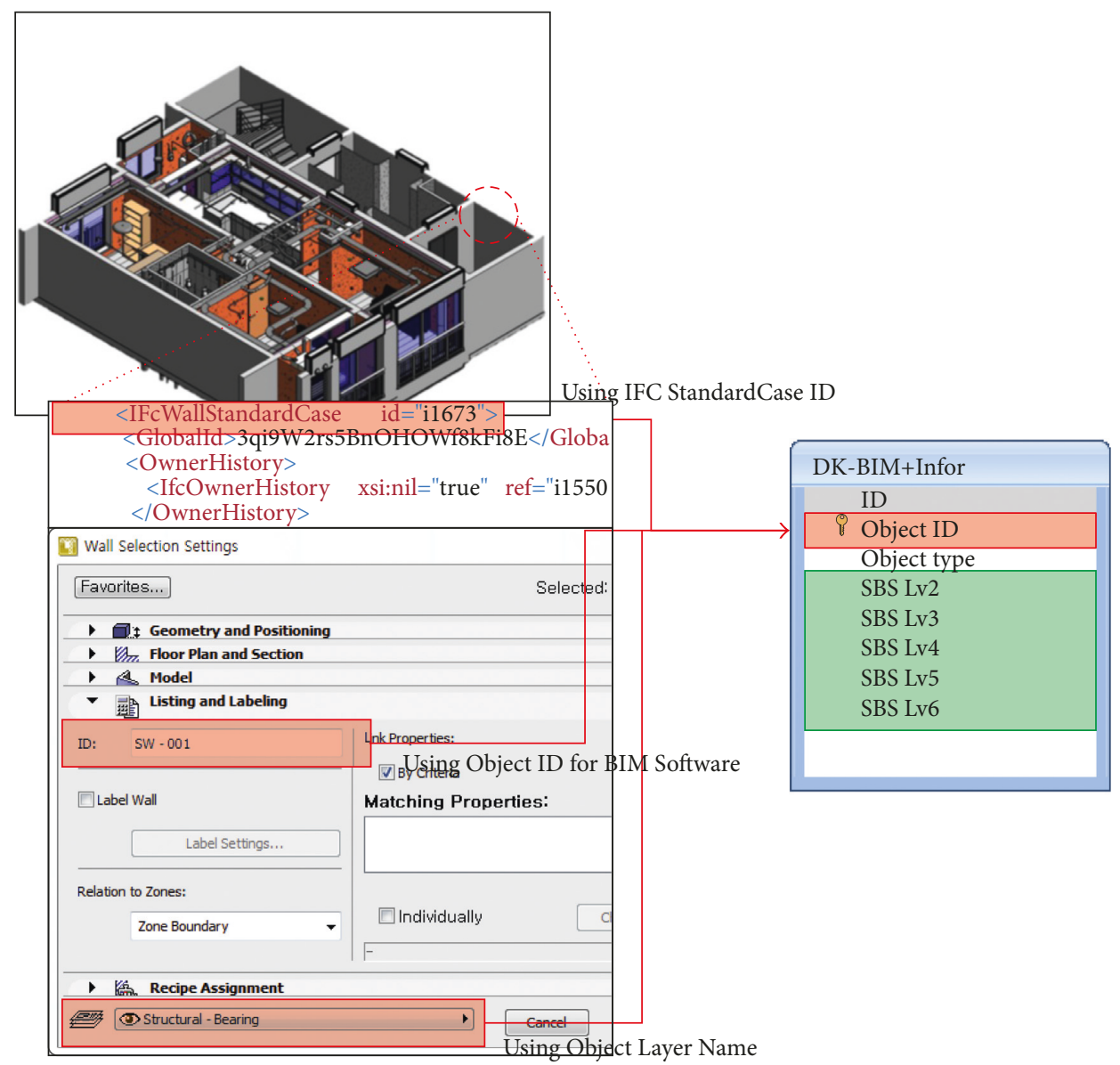

FIGURE 5: Methods of linking the BIM model with construction information.

construction site, it is possible to establish a system where the information generated at construction sites is gathered. Furthermore, in the case of nonstandardized information, the very documents containing such information can be stored as electronic documents, thus allowing for connections between all documented information pertinent to the construction, which in turn enables the review of all documented information involved with a given building's framework through linkage with the BIM model.

4.2. Designing a Construction Information Database. The construction information database consists of a spacecategorized $\mathrm{DB}$, site information $\mathrm{DB}$, work information $\mathrm{DB}$, and a DB for site-generated documents. Figure 8 depicts the linkage between construction information database and each data table.

When a construction site generates construction journal information, the information that can be stored as data (Part A of Figure 8) is entered into the system, and such entered data are stored into the site information database (Part E of Figure 8) and the work information database (Part F of Figure 8), and information that is difficult to be stored as data is transformed into an electronic document and stored on the onsite document database (Part C of Figure 8). Such entered site information is organized according to the form and subject by the information categorization system (Part B of Figure 8). The data tables of each database are linked based on the space categorization code, thereby linking the pertinent Object with the details of the work, site information, and so on. For example, Part D of Figure 8 shows the data tables included in the space-categorized database and includes data from Levels 1 to 6 of the space-based categorization system, and the project code information (SBS Lv 1) can be included in the site information database as shown in Part E of Figure 8, thus allowing for management with links to space information. And Part C of Figure 8 shows a sitedocument database for the storage of electronic documents by linking the electronic document form of construction site documents with the site code, the category information according to the information categorization system, and the space-based categorization system, while Part F of Figure 8 depicts a work information database that includes information on work schedules, information on workers, information on the details of the work, and categorization systems such as WBS and CBS.

\section{Scenario-Based Application of the Construction Information Database}

In this section, an attempt was made to test the effectiveness of the developed BIM-based construction information 


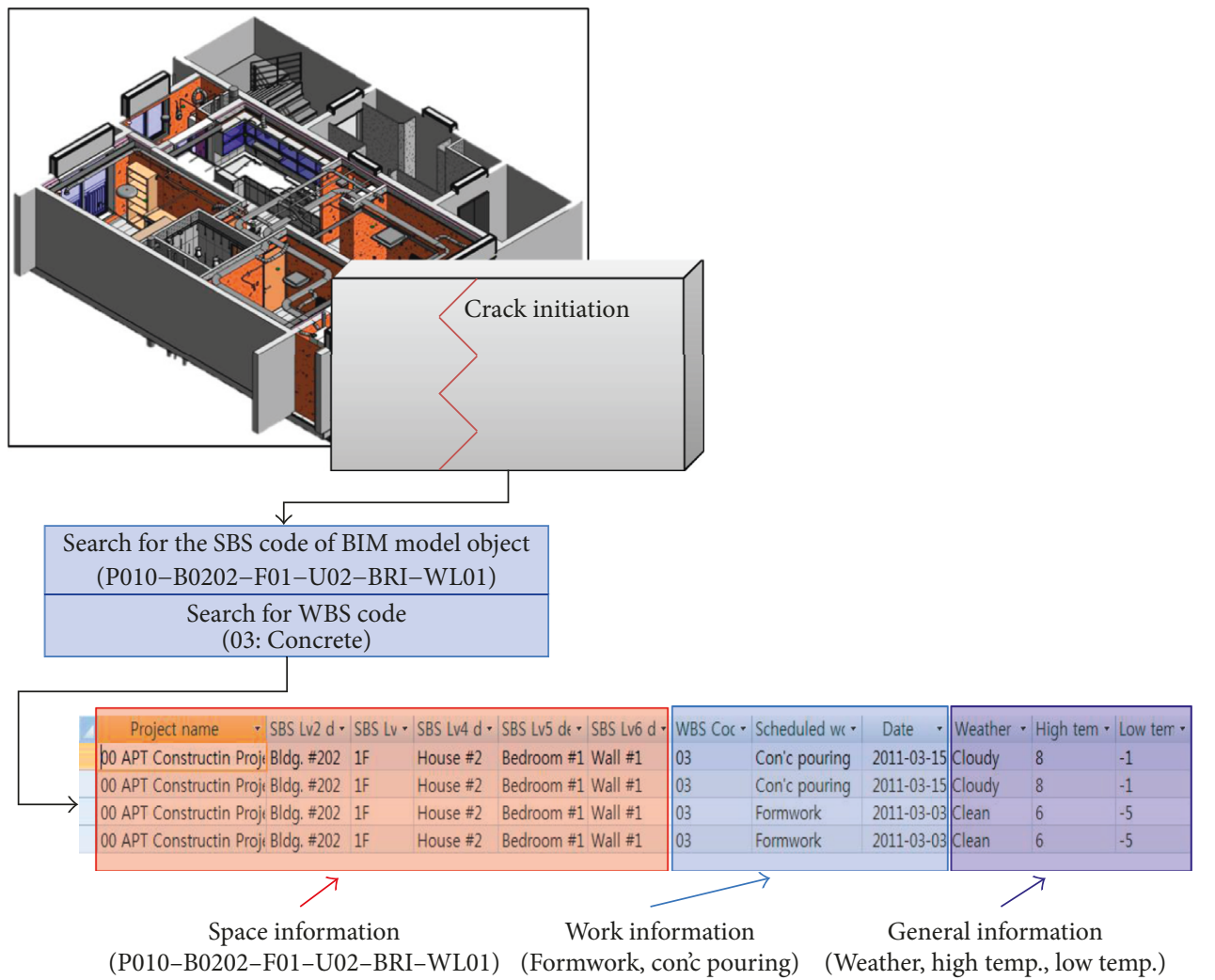

Figure 6: Example of using the BIM-based construction information database.

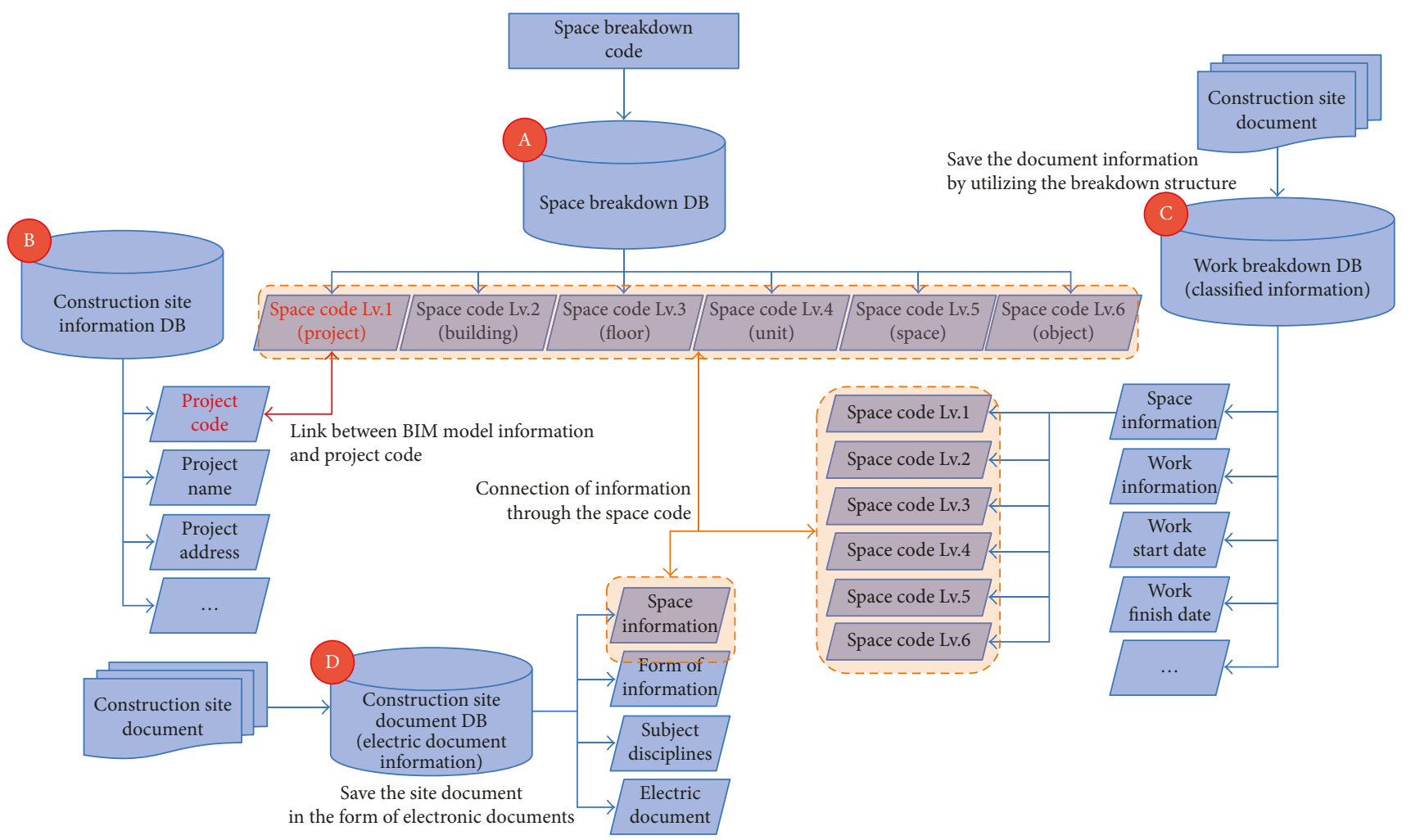

FiguRE 7: BIM-based database system for construction information. 


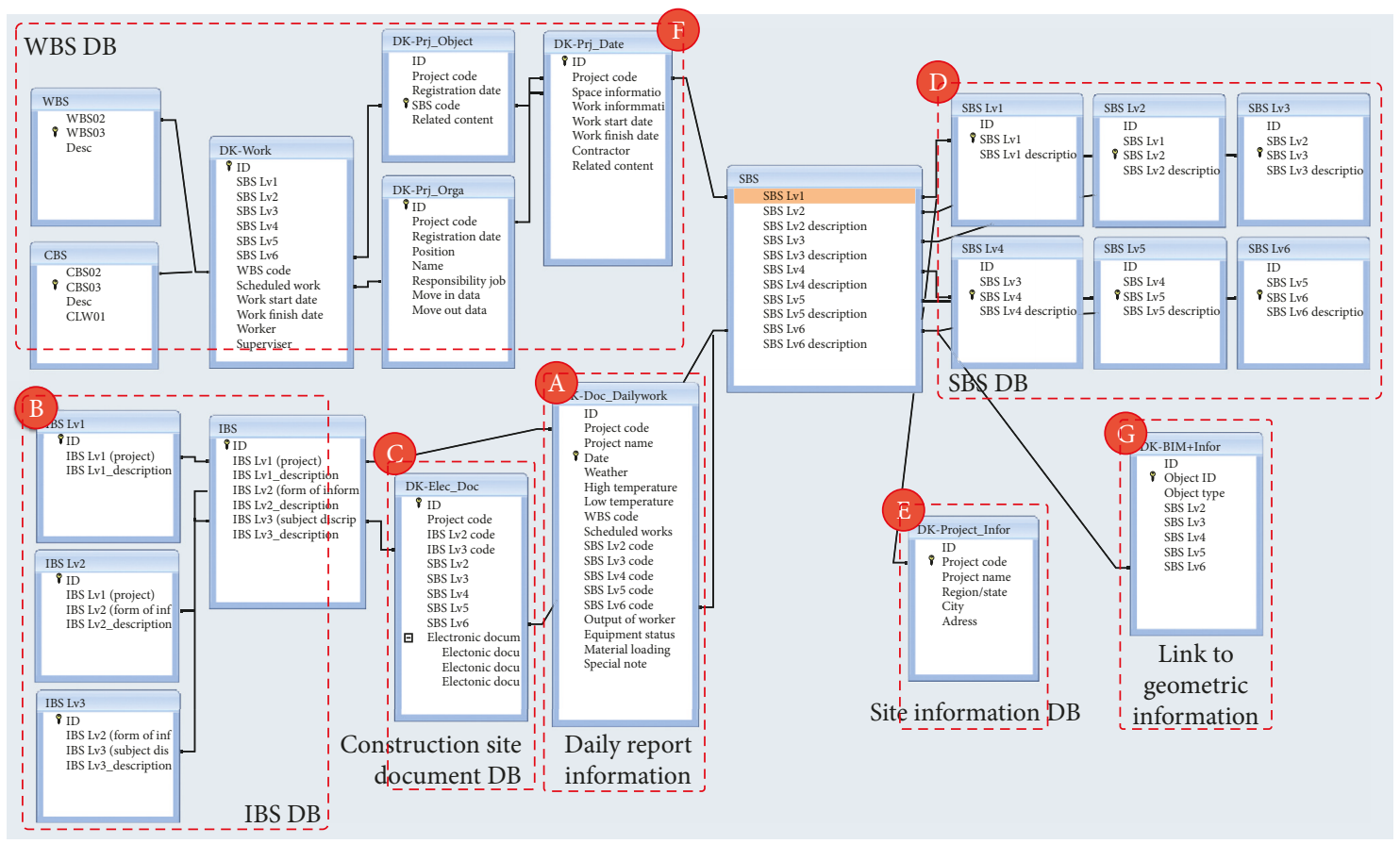

FIgURE 8: Connection relationships of the construction information database.

database. Since it is difficult to actually apply the construction information database to an actual construction site, an attempt was made to assess the possibility of implementing the database system based on a scenario. For this, based on the applied scenarios with respect to the storage and use of documents, an attempt was made to assess the possibility of implementing the construction information database through a process comparison between applying traditional processes and applying the information management database, thereby determining the effectiveness of the construction information database. In addition, the details of applying the construction information database were proposed. The scenarios in which the construction information database was to be applied were designed around the accumulation and storage of documented information generated by construction sites and the claims that arise after the completion of the construction project.

The scenarios for assessing the construction information database consisted of two phases: first, the process of managing the documents generated by construction sites and second, using stored information to determine the relevant documents in the case of a claim. The first phase, which is the process of managing the documents generated by construction sites, consisted of the steps in Parts A to D of Figure 1 and was implemented based on a scenario where the documents generated at construction sites were stored in the form of processed information and electronic documents that replicate the original documents. The second phase, which involved determining relevant documents for claims, consisted of the steps in Part E of Figure 1 and was a scenario involving the process of determining relevant documented information.
5.1. Scenario 1 (Management of Site-Generated Documents). Scenario 1 was a scenario concerning the accumulation and management of documents that are generated by construction sites, and through this scenario, a comparison was made between a process that uses traditional site-document management and a process that uses databases, and details on the information stored through the information management database were created.

At construction sites, the person in charge of preparing a document generated during the course of construction prepares a document, which is then reviewed by the relevant authorized persons (those in charge of quality management, those in charge of official affairs, deputy manager of the construction project, general manager, site manager, etc.), after which the construction begins. The prepared documents are stored in the form of personal files kept by the document preparer and in the form of documents stored in the document archive of the site; after construction is over, the documented information is turned into electronic documents and then uploaded to a management system such as PMIS.

The basic structure of document management using information management database is the same as that of the existing document management method. However, document management using an information management database will additionally build a database for information accumulation. This information management database stores the reorganized information that classifies the site-document information according to the ISB and additionally stores the e-documents of the actual site document. This process is advantageous in that it can enter into the database information generated by construction sites without omissions, thanks to the categorization of documented information 


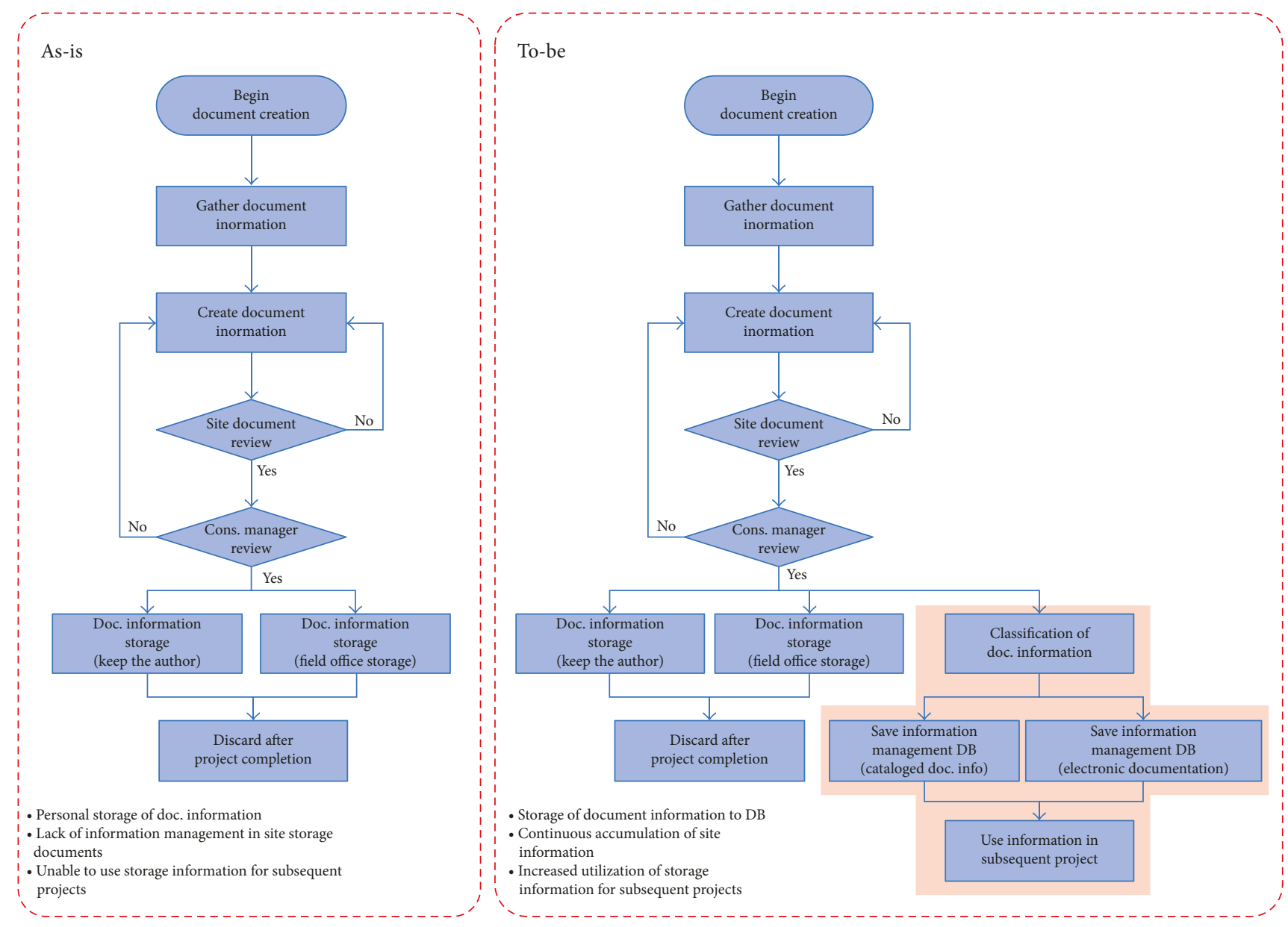

Figure 9: Comparison of document management methods.

generated onsite and the electronic storage of such documents. As such, the possibility of loss of information generated onsite is lowered, and searching for needed information is more convenient, thanks to the information database. Figure 9 depicts a comparison between the current method of management of documents generated at construction sites (As-is) and the method utilizing the information management database (To-be).

The current method of document management is not based on storage in a consolidated database but rather in individual storage or in onsite document archives. As such, when personnel that had been working on a particular construction site are redeployed to another site after the work is complete, the documents managed by individual preparers of documents are often dispersed, thus obstructing consolidated management of documents, while documents that are stored at the site are often not categorized, which reduces their usefulness and obstructs feedback for followup projects.

However, the method proposed in the present study not only provides for document management and storage by individual preparers and onsite document archives but also for information storage in a consolidated database, allowing for the consolidated management of the information generated by a construction site, as well as for the categorization of documented information through a categorization system, allowing for the effective use of the information and in turn enabling feedback for follow-up projects. While the process of storing prepared documented information into the database through categorization (the To-be shadowed part of Figure 9) requires time because the person in charge at the site must upload the information to a database, the additional storage of information facilitated by this process prevents problems such as information omissions.

The process of storing information into the construction information database consists of categorizing the documented information (the information generated part in Figure 10) contained in each site-generated document (the site-generated document part in Figure 10) using the categorization systems (SBS, IBS, etc.) and then storing the categorized information into each data table of the construction information database (the construction information database part in Figure 10). All documents are also replicated as electronic documents (Part A of Figure 10) and are also stored together with the corresponding documented information in the relevant data table of the database (Part B of Figure 10) and can be used as evidentiary materials in cases of claims and other problems in the future.

Furthermore, the data stored in the database have codes corresponding to each level of the SBS to enable linkage with the space-categorized database, which allows confirmation 


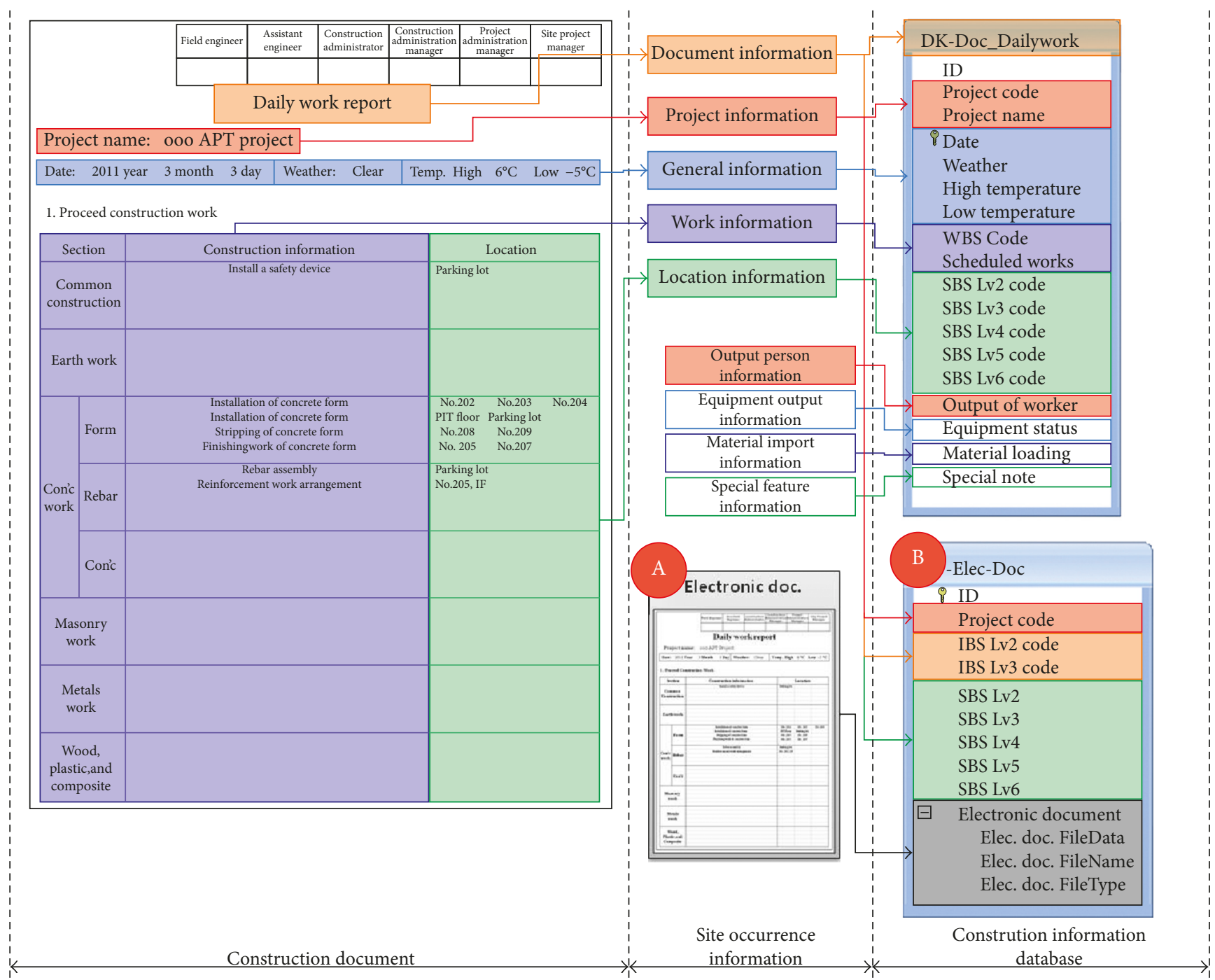

FIGURE 10: Storage of site-generated documents in the construction information database.

as to what stored information is linked to the framework of a given building. Through this method, documented information that is generated at construction sites is stored in the database, and the stored information is processed through the IBS and the SBS and managed as such, which allows for the reprocessing of stored information into information based on space and information based on type and form. Through this process, information generated through documents not only is stored as documents but can also be recategorized and reprocessed into new information depending on the needs of the user, which is expected to enable more efficient use of the stored information.

\subsection{Scenario 2 (Derivation of Relevant Documents in Cases of} Claims). Once a construction project is finished, claims are often filed against the project due to building defects. To pursue such a claim, one needs to conduct advance assessment, track down and secure evidentiary materials, analyze the evidentiary materials, substantiate the basis of the claim, calculate the expenses, prepare the necessary documents, and then submit the claim. Therefore, in order to successfully raise or defend against a claim, one would need to acquire sufficient evidentiary materials, and "tracking down evidentiary materials" is therefore considered very important in each phase of a claim. Furthermore, "tracking down evidentiary materials" requires much effort and resources; in this process, the documented information related to the claim that was generated during the course of the construction is collected.

Despite the fact that managing documented materials is very important as they can be used as evidentiary materials for a claim, current construction site management often overlooks the importance of document management in the context of raising or defending against claims, and document management often faces difficulties due to the urgent situations that arise at sites and due to overall construction management [24]. In order to collect the documents that may serve as evidentiary materials for a claim, it is necessary to collect information from the documents archived at the site or to collect the necessary documents by tracking down the person who was in charge of the documents. However, 


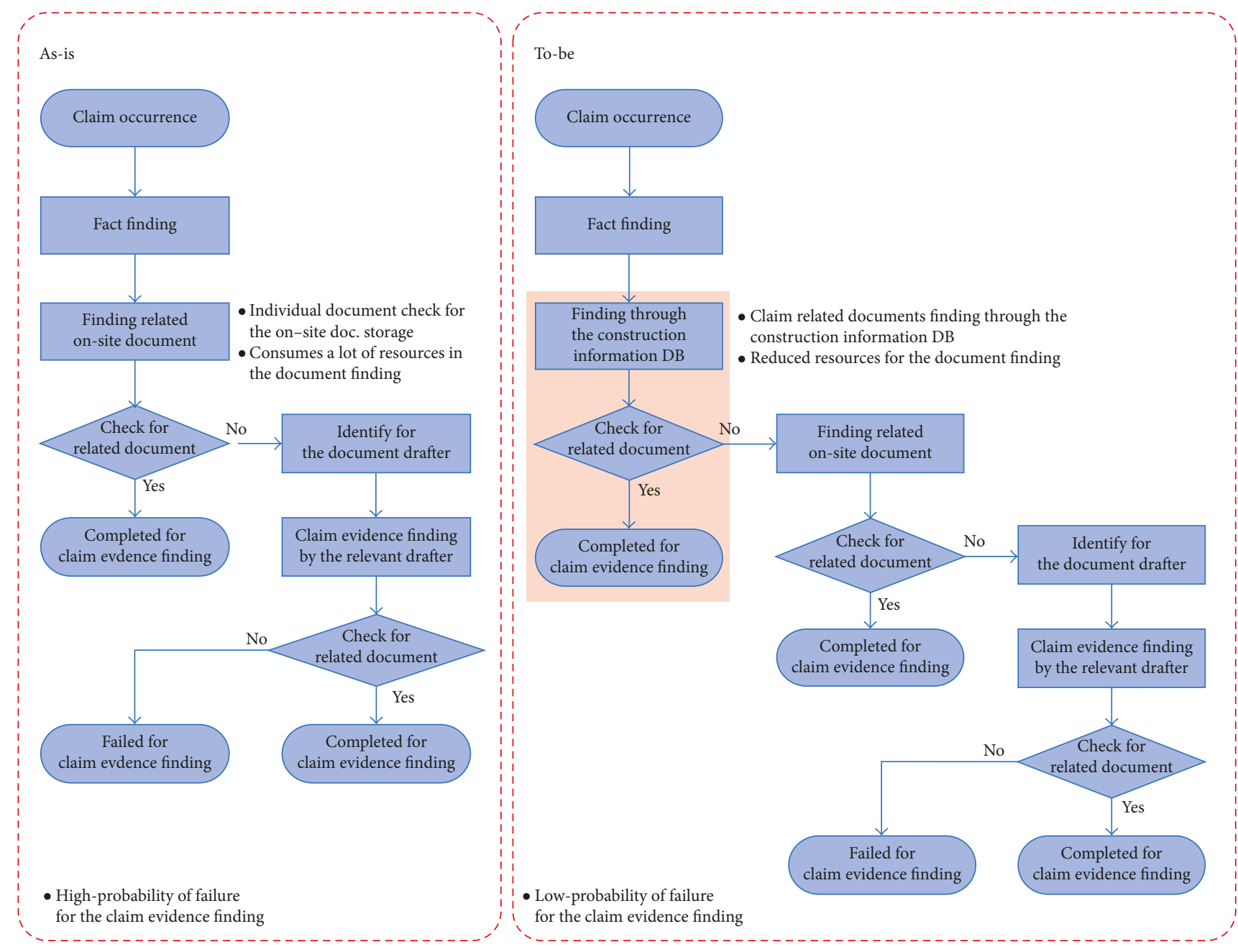

FIgURE 11: Comparison of claim materials' collection processes.

collecting claim-related documents from site-archived documents often faces the difficulty of having to invest much effort and resources in verifying and reviewing the numerous document files kept at the site. Also, trying to collect claim-related documented materials by tracking down the person in charge also often meets with difficulty because the personnel deployed to a project are often deployed to another project after the project is finished, which leads to the dispersion of documented information related to the claim.

However, the information management database proposed in this study allows for the convenient collection of claim-related documents through its system of categorization and the storage of electronic replicas of the documents generated by sites, which may precede physical review of the actual documents archived at the site, thus decreasing the possibility of failing at collecting claimrelated evidentiary materials. Furthermore, during the process of collecting information, the query and search system built into the database enables the expedient collection of information, while one may also confirm and review related information by selecting an Object in the linked BIM model. Figure 11 is a diagram depicting the claim material collection process under the current system and the collection process using the construction information database system.

According to an interview with an official in charge of handling claims at General Construction Company, while differences do exist across sites, sites with an insufficient document management system required about 3 4 hours for collecting claim-related evidentiary materials, while in about $5 \%$ of cases, the collection of evidentiary materials was difficult due to the loss of materials. As such, if document management is conducted by continuously inputting information into a construction information database during the course of construction, the time and resources needed to collect documented information regarding claims will be decreased, while the success rate for collecting such materials will in turn increase, enabling more expedient and accurate claim processing. This process can be implemented as shown in Figure 12.

The parameters that link the construction information database with the BIM model are inserted as elementary characteristics of the Object, and these inserted Parameters are composed as database access addresses that are linked to the construction information database (Part A of Figure 


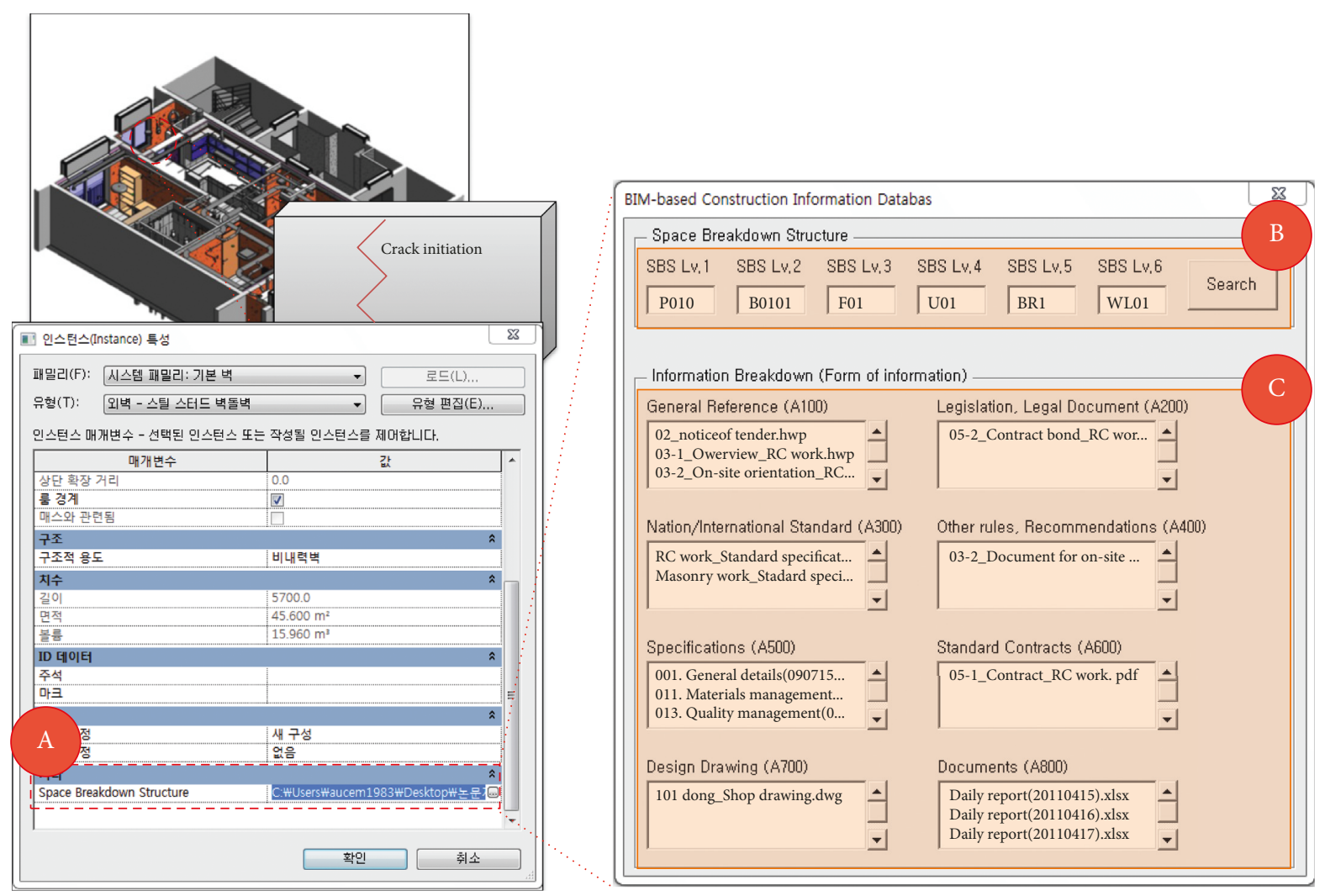

FIGURE 12: Database search screen for the collection of claim-related materials.

12). As for the construction information database linked to the BIM model, its user interface was composed with VBA (Visual Basic for Applications), and this user interface was composed so that the SBS and the electronic documents linked to the SBS would show the parts related to the IBS. When one searches the space-based categorization system pertinent to the framework in which the defect arose as in Part B of Figure 12, the information concerning the documents related to the relevant space-based categorization system is categorized based on the information categorization system and become available for verification as shown in Part $\mathrm{C}$ of Figure 12. In the case depicted in Figure 12, the electronic documents linked to the relevant framework are such that the specifications and construction journals were mutually linked, and therefore only the electronic documents relevant to said information appear.

The related construction documents are stored in the database through these linkages to the space-based categorization system of the pertinent framework using the BIM model; this enables the convenient review and confirmation of needed materials in cases of claims and other circumstances where the collection of documents on completed construction projects is needed, and it is expected that more systematic management of constructionrelated information will become possible through gathering related construction information into a construction information database using such information categorization systems.

\section{Conclusion and the Limits of the Study}

The construction industry is becoming increasingly complex, while the scale and number of participants in a project continue to grow, leading to the generation of large amounts of data as well as the need to manage such information. In particular, the construction phase is the phase in which the building itself is formed based on the blueprints and generates various types of data that need management. Since much of information during the construction phase is generated as documents, at present it is difficult to effectively gather the generated information.

In response, this study sought to propose a database system designed for data gathering and connections between structural and nonstructural information for the effective accumulation of construction information using BIM. For this purpose, a database system for information management based on a categorization system for documented information was proposed, and a proposal was also made to link structural and nonstructural information. In addition, the possibility of implementing such a database system was assessed through scenarios. The assessment showed that documented information could be extracted from the documents that were generated at construction sites and could form a database, while related documents could be extracted through the use of the gathered data.

It is believed that the results of this study will enable the formation of a system for gathering construction information by linking structural and nonstructural information, and it is 
also believed that the use of accumulated information for follow-up projects will aid in accumulation of know-how by construction companies.

However, while the BIM-based construction information database proposed in this study was formed based on the information generated by construction sites and through categorization systems for site-generated information, its viability was assessed through the use of scenarios rather than through direct application at actual construction sites and the attendant quantitative analysis of such direct application. As such, in order to further verify the anticipated effects of the model proposed in this study, it will be necessary to conduct an analysis through direct application at actual construction sites.

\section{Conflicts of Interest}

The authors declare that they have no conflicts of interest.

\section{Acknowledgments}

The research was supported by a grant (17RERP-B082173-04) from Residential Environment Research Program funded by Ministry of Land, Infrastructure and Transport of Korean Government.

\section{References}

[1] J. S. Choi, "A study on the development and application of quality control requirements for improving the quality of architectural design in open BIM environments [Ph.D. thesis]," Kyung Hee University, Yongin-si, Gyeonggi-do, Korea, 2011.

[2] Y. Jung, Y. Kim, M. Kim, and T. Ju, "Concept and structure of parametric object breakdown structure for practical BIM," Korean Journal of Construction Engineering and Management, vol. 14, no. 3, pp. 88-96, 2013.

[3] Y. S. Jung and M. H. Joo, "Patterns and trends in cost control practice of Korean general contractors," Korean Journal of Construction Engineering and Management, vol. 12, no. 4, pp. 79-87, 2011.

[4] Y. Jung and H. A. Kim, "Patterns and trends in schedule control practice of Korean general contractors," Korean Journal of Construction Engineering and Management, vol. 12, no. 4, pp. 88-96, 2011.

[5] Y. Jung and S. Woo, "Flexible work breakdown structure for integrated cost and schedule control," Journal of Construction Engineering and Management, vol. 130, no. 5, pp. 616-625, 2004.

[6] Y. Chen and J. M. Kamara, "A framework for using mobile computing for information management on construction sites," Automation in Construction, vol. 20, no. 7, pp. 776-778, 2011.

[7] H. C. Cho, "A study on the relationship of construction information documents control for automatic generation of construction documents," Ajou University, Suwon-si, Gyeonggido, Republic of KoreaAjou University, 2002 M.S. thesis, Thesis.

[8] S. K. Yang and K. W. Choung, "A study on the design of management information system for building construction sites," Journal of the Architectural Institute of Korea Structure \& Construction, vol. 4, no. 3, pp. 153-160, 1988.

[9] P. G. Ioannou and L. Y. Liu, "Advanced construction technology system-ACTS," Journal of Construction Engineering and Management, vol. 119, no. 2, pp. 288-306, 1993.
[10] R. Furchter and K. Reiner, "Model-centered World Wide Web coach," in Proceeding of ASCE 3rd Congress Computing in Civil Engineering, Anaheim, CA, USA, 1996.

[11] S. Simoff and M. L. Maher, "Ontology-based multimedia data mining for design information retrieval," in Proceeding of ASCE Computing Congress, Cambridge, UK, 1998.

[12] D. Hajjar and S. M. AbouRizk, "Integrating document management with project and company data," Journal of Computing in Civil Engineering, vol. 14, no. 1, pp. 70-77, 2000.

[13] B. Kosovac, T. M. Froese, and D. J. Vanier, "Integrating heterogeneous data representations in model-based AEC-FM systems," in Proceeding of CIT 2000-The CIB-W78, IABSE, EG-SEA-AI International Conference on Construction Information Technology, Reykjavik, Iceland, June 2000.

[14] C. H. Caldas and L. Soibelman, "Automating hierarchical document classification for construction management information system," Automation in Construction, vol. 12, no. 4, pp. 395-406, 2003.

[15] M. S. Park, K. W. Lee, and H. S. Lee, “Ontology framework for construction knowledge retrieval," Journal of the Architectural Institute of Korea Structure \& Construction, vol. 25, no. 12, pp. 175-184, 2009.

[16] H. J. Park, "Tag-manager based document management prototype system of building material information [M.S. thesis]," University of Seoul, Seoul, Korea, 2009.

[17] S. G. Lee, "Metadata-library based document management prototype system for urban renewal promotion plan [M.S. thesis]," University of Seoul, Seoul, Korea, 2009.

[18] N. Dawood, E. Sriprasert, Z. Mallasi, and B. Hobbs, "Development of an integrated information resource base for $4 \mathrm{D} / \mathrm{VR}$ construction processes simulation," Automation in Construction, vol. 12, no. 2, pp. 123-131, 2003.

[19] C. H. Caldas, L. Soibelman, and L. Gasser, "Methodology for the integration of project documents in model-based information systems," Journal of Computing in Civil Engineering, vol. 19, no. 1, pp. 25-33, 2005.

[20] C. M. Eastman, Y. S. Jeong, R. Sacks, and I. Kaner, "Exchange model and exchange object concepts for implementation of national BIM standards," Journal of Computing in Civil Engineering, vol. 24, no. 1, pp. 25-34, 2010.

[21] R. Liu and R. R. A. Issa, "Automatically updating maintenance information from a BIM database," in Proceedings of International Conference on Computing in Civil Engineering, Clearwater Beach, FL, USA, June 2012.

[22] Z. Ma, Z. Wei, and X. Zhang, "Semi-automatic and specification-compliant cost estimation for tendering of building projects based on IFC data of design model," $A u$ tomation in Construction, vol. 30, pp. 126-135, 2013.

[23] Y. C. Lin, "Construction 3D BIM-based knowledge management system," Journal of Civil Engineering and Management, vol. 20, no. 2, pp. 186-200, 2014.

[24] J. H. Seo, "Study for analysis on the level of claim management system of construction firm for coping with claim," M.S. thesis, Sungkyunkwan University, Suwon, Korea, 2011. 


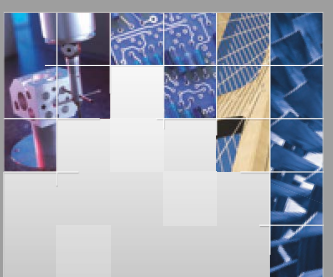

\section{Enfincering}
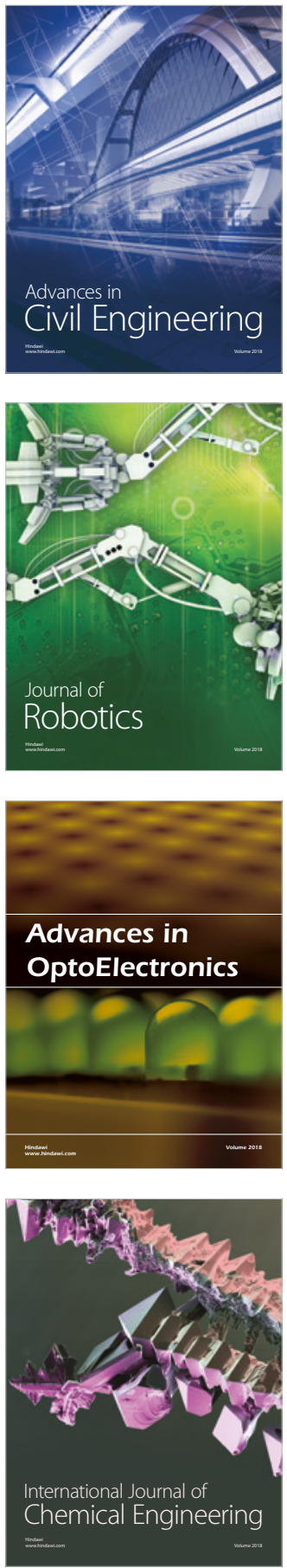

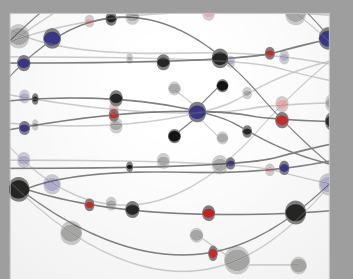

\section{Rotating \\ Machinery}

The Scientific World Journal

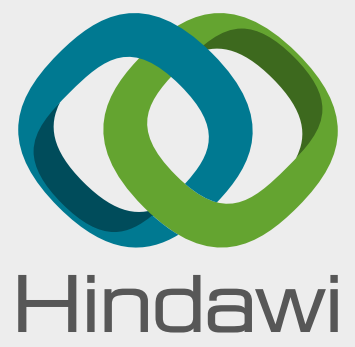

Submit your manuscripts at

www.hindawi.com
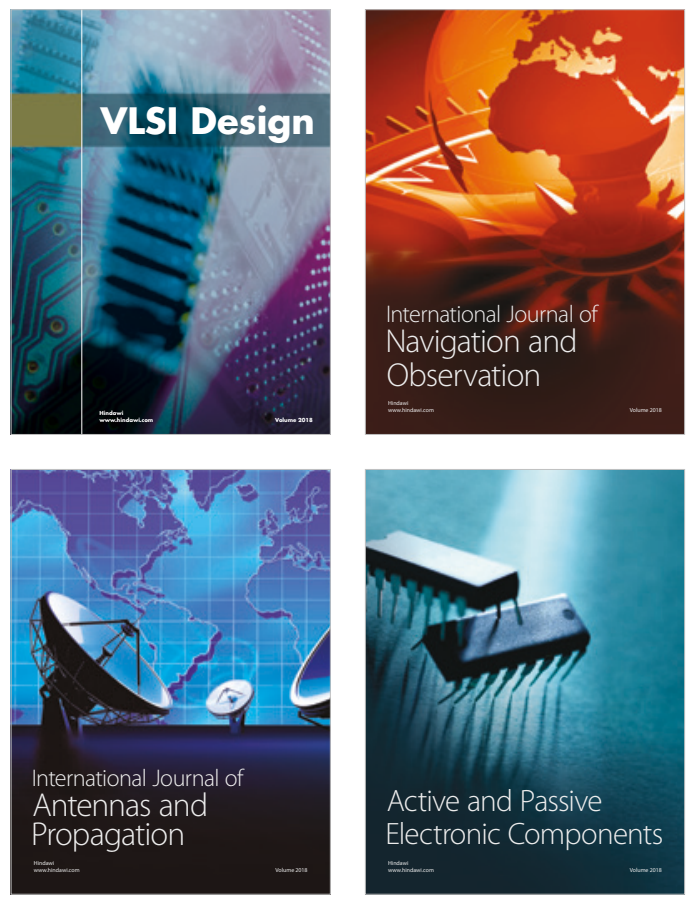
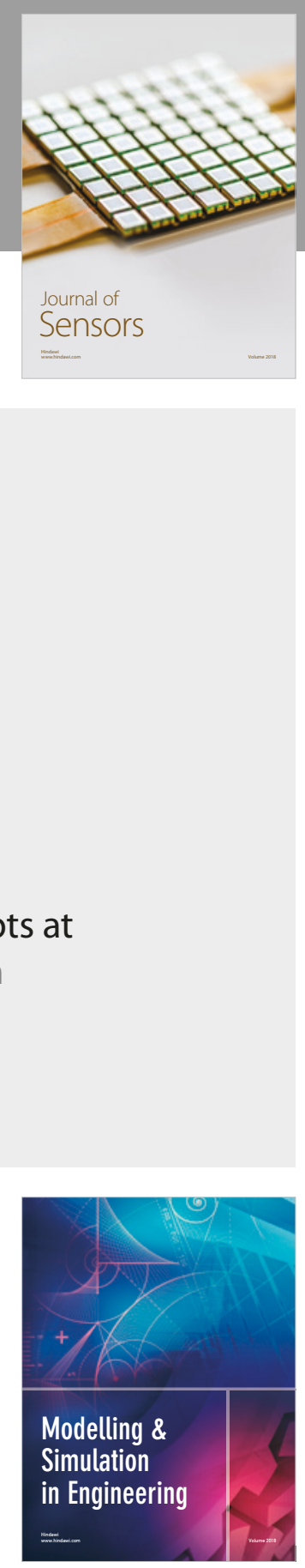

\section{Advances \\ Multimedia}
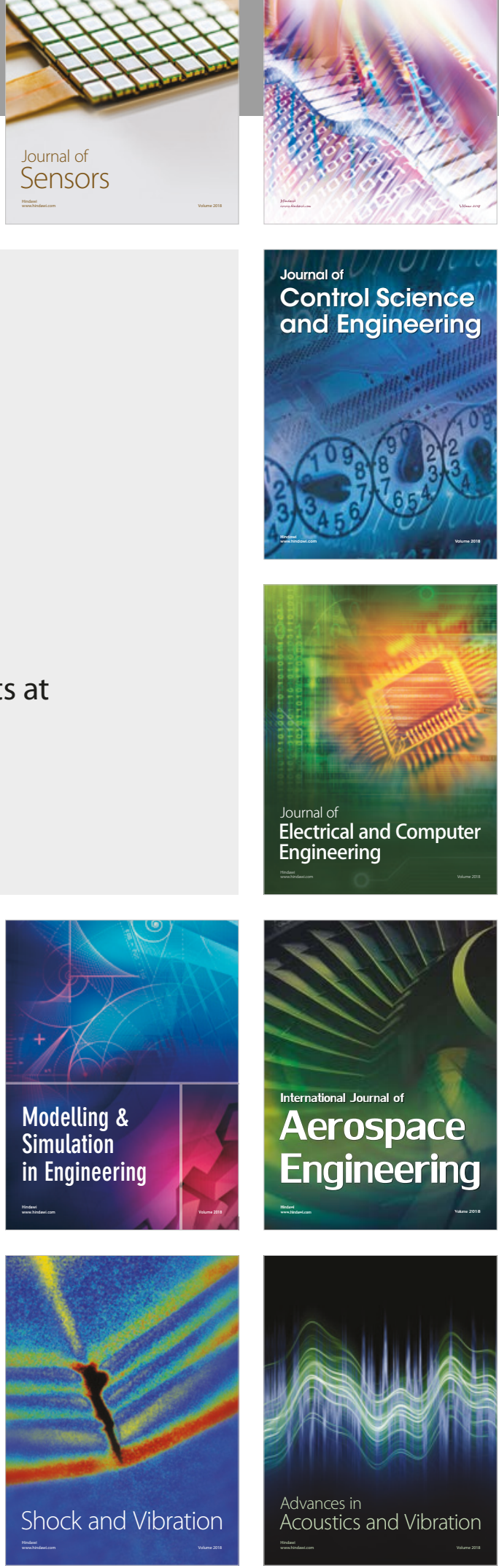